\title{
ARTIGO
}

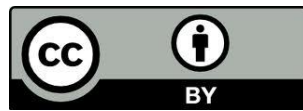

\section{NOVAS VIVÊNCIAS DO SAGRADO: PADRE REGINALDO MANZOTTI E A RELIGIOSIDADE VIRTUAL NO BRASIL ${ }^{1}$ \\ New Experiences of the Sacred: Father Reginaldo Manzotti and Virtual Religiosity in Brazil}

Mariela Passarin Graduada em História pela Universidade Federal do Paraná marielapassarin@gmail.com

RESUMO: A partir de um cenário religioso em transformação e diante de uma sociedade midiatizada, a Igreja Católica se vê pressionada a modernizar sua estrutura de comunicação intensificando a utilização da mídia de massa. Acompanhando a evolução desses meios, a evangelização católica estende-se ao ambiente digital. No Brasil, observa-se que com o advento da Internet alguns padres, configurados como midiáticos, reconstroem práticas católicas tidas como tradicionais e transformam a religiosidade no ciberespaço. Com base em uma perspectiva histórico-cultural, são analisadas neste artigo as relações entre o catolicismo e os meios de comunicação de massa. Esse hibridismo entre catolicismo e mídia é representado nessa pesquisa, a partir das práticas virtualizadas de evangelização do padre Reginaldo Manzotti e da interação dos fiéis com as novas vivências do sagrado.

Palavras-chave: Mídia Religiosa; Padres Cantores; Evangelização Virtual

ABSTRACT: From a changing religious scene and before a mediatized society, the Catholic Church is under pressure to modernize its communication structure, intensifying the use of mass media. Accompanying the evolution of these means, catholic evangelization extends to the digital environment. In Brazil, it is observed that with the advent of the internet some priests, configured as mediatic, reconstruct catholic practices considered as traditional and transform religiosity into cyberspace. Based on a historical-cultural perspective, this article analyzes the relationship between catholicism and the mass media. This hybridism between Catholicism and the media is represented in this research, based on the virtualized practices of evangelization of Father Reginaldo Manzotti and the interaction of the faithful with the new experiences of the sacred.

Keywords: Religious Media; Singer Priests; Vrtual Evangelization.

\footnotetext{
${ }^{1}$ Este artigo origina-se da monografia de graduação no Curso de História da Universidade Federal do Paraná, sob orientação da professora doutora Karina Kosicki Bellotti
} 


\section{Introdução}

A partir de meados do século XX, diante de uma crise no catolicismo universal, a Igreja Católica se vê pressionada a modernizar sua estrutura de comunicação intensificando a utilização da mídia de massa. Acompanhando a evolução desses meios, a evangelização católica estende-se ao ambiente digital. No Brasil, observa-se que com o advento da Internet alguns padres, configurados como midiáticos, reconstroem práticas católicas tidas como tradicionais e transformam a religiosidade no ciberespaço.

Com base nesse cenário, objetiva-se analisar, a partir de uma perspectiva histórico-cultural, as relações entre o catolicismo e os meios de comunicação de massa, bem como investigar o impacto dessa relação histórico-evolutiva adotando-se, como base, as práticas virtualizadas de evangelização do padre Reginaldo Manzotti. O estudo se orienta em torno de três questões centrais: o desafio da "ética católica" relacionado à exploração religiosa da mídia; a modernização das práticas evangelizadoras tradicionais e as novas formas de religiosidade; e o entrelaçamento das relações entre "sagrado e profano" no comércio religioso online.

Em um contexto de hibridismo entre a religião católica e mídia moderna no Brasil, observa-se que a interação do catolicismo com os meios de comunicação ocorre, no Brasil, com base em seus veículos próprios ${ }^{2}$, e intensifica-se frente a uma forte concorrência religiosa no país (BELLOTTI, 2012, p. 134). E é como reação a esse mercado que surgem, vinculados à Renovação Carismática Católica (RCC), os padres midiáticos, exemplificado nessa pesquisa a partir do padre Reginaldo Manzotti - cantor, escritor e apresentador paranaense. Intitulado em seus diversos canais de comunicação como "o padre que arrasta multidões e evangeliza pelos meios de comunicação"3, Manzotti lançou livros, CDs e DVDs musicais, realiza missas seguidas de shows e apresenta programas de rádio e televisão que são retransmitidos e exibidos em milhares de emissoras do país e no exterior ${ }^{4}$.

Pertencente à arquidiocese de Curitiba, o padre Reginaldo opera como pároco no

\footnotetext{
2 Data de 1941 a primeira "concessão católica” (Rádio Excelsior de Salvador). PUNTEL, Joana T. Catolicismo e Mídia no Brasil. In: MOREIRA, Alberto da S.; LEMOS, Carolina T.; QUADROS, Eduardo de G. (organizadores). A Religião na Mídia e a Mídia na Religião. Goiânia: América, 2012. p. 35-37.

${ }^{3}$ Perfil oficial do Padre Reginaldo Manzotti no Facebook. Disponível em: <https://www.facebook.com/padrereginaldomanzotti>. Acesso em: 04 jun. 2014.

4 Página oficial do Padre Reginaldo Manzotti na Internet. Disponível em: <http://www.padrereginaldomanzotti.org.br/>. Acesso em: 06 jun. 2014.
} 
Santuário Nossa Senhora de Guadalupe, e é fundador do movimento evangelizador Associação Evangelizar é Preciso. Atuando com intensidade nos meios de comunicação de massa, o sacerdote destaca-se cada vez mais por suas práticas religiosas virtuais. Contudo, apesar de seu sucesso com o público católico, até o momento, são raros os estudos a respeito da sua evangelização midiatizada. A partir do seu ministério online observa-se, dentro da dinâmica desse processo modernizante, como a Igreja lança mão da mídia de massa em um renovado processo de evangelização no ciberespaço ${ }^{5}$.

Sendo assim, são abordados nesse artigo contornos específicos envolvendo as práticas virtualizadas do comunicador, como a nova relação com o tempo e com o espaço, na qual experiências religiosas online são vivenciadas a partir de qualquer local e horário (AOKI; MACHADO, 2010, p. 106-122); a linguagem simplificada permitida pelo mundo digital; e a interação direta e mais livre do fiel com a religião. Da mesma forma, analisam-se outros aspectos com os quais o padre se depara na Internet, como a falta de controle sobre conteúdos religiosos e sobre a autonomia dos leigos. As fontes também permitem a investigação do extenso comércio religioso que se desenvolve em torno da figura do Padre Reginaldo Manzotti, levando a uma reflexão em torno do entrelaçamento entre os conceitos de sagrado e profano no espaço religioso virtual.

\section{Aspectos das práticas virtualizadas de evangelização do Padre Reginaldo Manzotti}

A análise do ministério comunicacional do padre Reginaldo Manzotti na Internet leva a algumas reflexões próprias da inter-relação entre religião e mídia virtual. É inegável que a cibercultura permitiu uma nova vivência da religiosidade. Os recursos utilizados pelo padre Reginaldo em suas práticas evangelizadoras unem ferramentas de vários outros meios de comunicação; trata-se de uma "linguagem hipermidiática", pois se utilizam, em um mesmo ambiente e momento, textos, sons, vídeos e imagens ferramentas que amplificam as formas tidas até então como tradicionais na evangelização católica (AOKI; MACHADO, 2010, p. 106-122). Ao acompanhar a evolução da tecnologia da comunicação, o sacerdote acaba por se sujeitar aos desafios e às oportunidades que a nova era virtual oferece à evangelização no ciberespaço (PUNTEL; CORAZZA, 2007, p. 70).

\footnotetext{
${ }^{5}$ Pelo prisma histórico-cultural, Karina Bellotti insere a presença da religião na Internet dentro de um contexto mais amplo, do cristianismo ocidental e do sistema comunicacional do século XX, articulando "a questão da religião e dos seus usos de comunicação" com o conceito de tradição "e suas relações com a modernidade”. BELLOTTI, Karina K. As Religiões..., p. 129.
} 
Possivelmente a principal característica da religiosidade no ambiente virtual esteja vinculada às novas formas de se lidar com o tempo e com o espaço ${ }^{6}$. Através das diversas redes sociais nas quais o padre Manzotti atua, o acesso aos seus muitos recursos digitais pode ser simultâneo e dentro de um mesmo ambiente. A página do

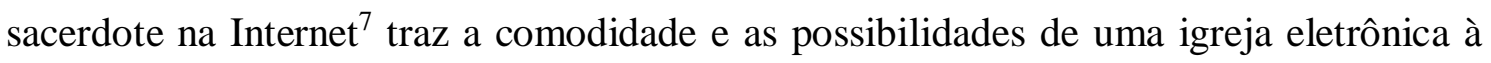
velocidade de apenas alguns clicks. Como reconhece o Vaticano, a Internet oferece aos indivíduos "um acesso directo e imediato a importantes recursos religiosos e espirituais"8. Os fiéis, especialmente aqueles de grandes aglomerados urbanos, a exemplo de Curitiba, são atraídos pelo conforto e praticidade da experiência religiosa online, que pode ser vivenciada a partir de qualquer local e horário, necessitando apenas de um computador com acesso à rede (AOKI; MACHADO, 2010, p. 106-122). Como o próprio padre expõe, a população moderna já não adapta mais seus horários em função do funcionamento tradicional das igrejas: "os horários das igrejas estão equivocados, abrem as nove e fecham as dezoito, o povo está no trabalho, o povo quer rezar depois do seu expediente de trabalho [...]"9.

\begin{abstract}
A mídia religiosa há muito tempo tem sido vista como concorrência para as instituições religiosas tradicionais por uma série de razões: ela é conveniente (você não precisa deixar sua casa para ver um sermão, ou uma telenovela sobre o assunto), ela permite escolha (você pode assistir um evangélico por um minuto e no instante seguinte entrar num igreja virtual), ela proporciona anonimato (frequentar uma Igreja é uma forte declaração pública; assistir a uma televangelista não); ela é democratizada (acessível a todos). (EINSTEN, 2012, p. 17-18)
\end{abstract}

A comunicação religiosa no mundo virtual também permite uma linguagem simplificada, curta e dinâmica, a exemplo dos tweets diários publicados pelo padre Reginaldo, bem como mensagens de orações e releituras de trechos da Bíblia afastando-se das leituras católicas tradicionais complexas, extensas e de mais difícil compreensão.

\footnotetext{
${ }^{6}$ Entrevista com Moisés Sbardelotto autor do livro E o Verbo se fez Bit - A comunicação e a experiência religiosas na internet. Disponível em:

$<\mathrm{http}: / /$ editorasantuario.wordpress.com/2012/11/09/entrevista-com-moises-sbardelotto-autor-do-livro-eo-verbo-se-fez-bit-a-comunicacao-e-a-experiencia-religiosas-na-internet/>. Acesso em: 20 out. 2104.

${ }^{7}$ Página oficial do Padre Reginaldo Manzotti na Internet. Disponível em:

<http://www.padrereginaldomanzotti.org.br/>. Acesso em: 06 jun. 2014.

${ }^{8}$ Igreja e Internet (28 de Fevereiro de 2002). Item 5. In: Conselho Pontifício para as Comunicações Sociais.

<http://www.vatican.va/roman_curia/pontifical_councils/pccs/documents/rc_pc_pccs_doc_20020228_ch urch-internet_po.html>. Acesso em: 07 jul. 2014.

${ }^{9}$ Programa Mais Você com Ana Maria Braga exibido em 25/12/2012. Disponível em:

<https://www.youtube.com/watch?v=vQEZBrcy3NQ>. Acesso em: 25 set. 2014.
} 
Além das facilidades de horário e acesso, observa-se a partir da atuação do padre Reginaldo Manzotti que as práticas virtualizadas da religião permitem uma interação direta e mais livre do fiel - a relação da religião com o público passa também para a relação do público com a religião; no ambiente online, o devoto se transforma de mero receptor para colaborador na construção da religiosidade. Sendo, no ciberespaço, essa troca muito mais intensa e frequente, que as possíveis e oferecidas nas práticas católicas presenciais - devido ao rigor dos rituais e discursos. Como afirma Einstein (2012, p. 25), “[...] a televisão não é o meio ideal para apresentar [...] formas novas de prática espiritual. A Internet, por outro lado, é quase perfeita". Exemplo dessa inter-relação são as muitas publicações do padre Reginaldo em redes sociais citadas anteriormente, como o Facebook, que alcançam milhares de participações entre comentários, curtidas e compartilhamentos. Essa multidão de devotos leva também à questão da amplitude de alcance que o padre Reginaldo obtém através da evangelização online. Em um país com crise nas vocações sacerdotais, um único padre acessa um público de mais de 4 milhões de seguidores em uma única rede social da Internet.

Outro aspecto interessante das práticas virtuais do padre Manzotti está na apropriação que ele faz de elementos da prática popular, justamente daquelas que na manifestação presencial dispensam a intermediação de um sacerdote, como a crença em milagres e o culto aos santos: "a dinâmica desta religiosidade 'dispensava' a presença dos representantes oficiais da Igreja (os padres), gozando, assim de ampla liberdade" Teixeira (2009, p. 20). Dessa forma, o comunicador consegue incorporar as práticas populares, evitando uma possível autonomia do fiel, ao mesmo passo em que reforça a figura do sacerdote como intermediador necessário ou mesmo indispensável à comunicação com o sagrado. Quando o padre em suas postagens no Facebook ou no Twitter convida os fiéis a rezarem e a pedirem por milagres, a essas publicações seguem centenas de comentários com depoimentos de devotos, registrando seus agradecimentos e pedidos individuais de milagres. Outro exemplo dessa assimilação de cultos populares pelo sacerdote está no Boletim Informativo Semanal do padre. Através da newsletter o padre Manzotti apropria-se da popular prática do culto aos santos que, conforme Teixeira (2009, p. 20), desde o período da colonização, constitui uma das manifestações católicas mais tradicionais no Brasil, ligada à sua formação cultural-religiosa.

Através de publicações diárias nas redes sociais em homenagem a determinados 
santos do dia, ou aos mais conhecidos nacionalmente, ou ainda por meio de mensagens por e-mail no newsletter, o padre traduz para a linguagem virtual a familiaridade que os fiéis mantem com seus santos e, no mundo digital, assume o papel de intermediário dessa crença e prática devocional. Contudo, no ciberespaço, o tradicional contato físico do fiel com seu santo é substituído pelo culto às imagens dos mesmos, que sempre acompanham as publicações do padre a esse respeito - especialmente nas redes sociais, mantendo assim a "materialização do sagrado". Possivelmente, ao enfatizar o culto aos santos, o sacerdote também busque uma afirmação da identidade católica como forma de enfrentar a concorrência, também no ambiente online (SOUZA, 2005, p. 162). Considerando-se que no Brasil, apesar de o culto aos santos servir como uma manifestação da "vitalidade do catolicismo", também funciona como um demarcador dentro do cristianismo entre os católicos, para os quais esse culto é legítimo, e os evangélicos, que “o condenam enquanto idolatria” Menezes (2009, p. 110).

Intermediando essas práticas populares, o padre Reginaldo também controla de certa forma a "relativa autonomia com respeito ao catolicismo institucional". Tem-se, portanto, que apesar do impacto que o processo de romanização ${ }^{10}$ causou sobre essa forma mais popular e independente da religiosidade católica no Brasil, as "concepções basilares do catolicismo popular tradicional" como o culto aos santos e a crença em milagres permaneceram presentes (TEIXEIRA, 2009, p. 21). Estudos recentes apontam as festas, as devoções aos santos, as romarias, por exemplo, como práticas bastante presentes na religiosidade popular e mantenedoras de uma certa autonomia em relação "ao clero e ao discurso oficial católico" Mariz (2006, p. 62-63).

\section{Reflexos da comunicação religiosa virtual}

A partir de análise de documentos da Igreja em torno da comunicação, verificase que, já a partir da década de 1970, a instituição reconhecia as conveniências da interação religiosa não presencial por meio dos meios de comunicação de massa: "os modernos meios de comunicação social dão ao homem de hoje novas possibilidades de confronto com a mensagem evangélica; permitem aos cristãos seguir, mesmo de longe,

\footnotetext{
${ }^{10}$ De acordo com Teixeira, a romanização "marcou o processo de instauração no Brasil de um 'catolicismo universalista', caracterizado pelo maior controle sobre os leigos e suas associações e de adequação do catolicismo brasileiro às diretrizes centralizadoras de Roma”. TEIXEIRA, Faustino. Faces..., p. 21.
} 
as cerimónias religiosas" "11. Ainda assim, vale ressaltar que a Igreja não reconhece as práticas religiosas virtuais, por exemplo, como substitutivas das presenciais (AOKI; MACHADO, 2010, p. 106-122).

Contudo, atualmente, observa-se que essas práticas religiosas à distância, especialmente as virtuais, tem sido relacionadas ao declínio do número de fiéis nas celebrações católicas presenciais e encontros físicos de grupos de devotos. Como explica Alberto Moreira, um exemplo desse fenômeno estaria vinculado à divisão das comunidades religiosas em reais e virtuais, processo no qual "a comunicade virtual se afirma e a comunidade geográfica se redimensiona". Todavia, na visão do autor, apesar de atualmente existir uma comunicação entre as duas, a tendência é que apenas as comunidades formadas no ciberespaço se mantenham vivas e se especializem (MOREIRA, 2012, p. 123). Do mesmo ponto de vista partilha Joana Puntel quando afirma que esse novo modo virtualizado de fazer religião pode estar afetando as comunidades presenciais e possivelmente ocasionando um deslocamento da religião para as comunidades midiáticas (PUNTEL, 2012, p. 42). Contudo, Karina Bellotti apresenta outro ponto de análise, de acordo com o qual, o mundo virtual não necessariamente substitui o "real". A Internet, respeitadas as suas particularidades, deve ser vista "como mais uma ferramenta a ser incorporada a um repertório de meios de comunicação já utilizados por algumas religiões institucionais”. A autora menciona uma pesquisa realizada com jovens, adeptos religiosos, nos Estados Unidos, que aponta que os indivíduos que buscam a Internet "por razões espirituais" com uma frequência de ao menos três vezes por semana, igualmente tendem a participar presencialmente de forma mais ativa em sua religião, utilizando a Internet para "incrementar suas atividades religiosas 'offline', ao invés de substituí-las". Bellotti ressalta ainda, que semelhante preocupação de "sobreposição do mundo 'real' pelo midiático", surgiu também quando ascenderam outros veículos de massa potenciais para a evangelização, como o rádio e a televisão ${ }^{12}$. Com base nessa última interpretação observa-se, a partir da pregação do Padre Reginaldo, que o comunicador adota no virtual e no offline uma relação de

\footnotetext{
${ }^{11}$ Instrução Pastoral Communio et progressio (23 de Maio de 1971). In: Conselho Pontifício para as Comunicações Sociais. Disponível em: $<$ http://www.vatican.va/roman_curia/pontifical_councils/pccs/documents/rc_pc_pccs_doc_23051971_co mmunio_po.html $>$. Capítulo 2, item 128. Acesso em: 07 jul. 2014.

${ }^{12} \mathrm{O}$ projeto mencionado intitula-se "Pew Internet \& American Life Project: CyberFaith: How Americans Pursue Religion Online” de Elena Larsen. BELLOTTI, Karina K. As Religiões..., p. 133.
} 
complementaridade e integração, na qual as práticas online reforçam as presenciais e vice-versa.

Apesar de a Internet oferecer uma amplitude de acesso a diversos públicos, em sua prática religiosa online, o padre Reginaldo depara-se com a falta de controle sobre os conteúdos religiosos e sobre a autonomia dos leigos:

Do ponto de vista religioso, são sobretudo os leigos, ou seja, os nãoteólogos e não-especialistas do sagrado, ainda que experts em informática e linguagem computacional, que tomam a iniciativa e configuram os novos espaços e modalidades de experiência do sagrado nos mundos virtuais. (MOREIRA, 2012, p. 123)

Apesar do desejo da Igreja em obter e controlar esse meio digital - por sua amplitude de alcance e fácil acessibilidade -, o ciberespaço também permitiu aos leigos criarem e manobrarem, autonomamente, novas experiências de fé e vivência com o sagrado:

[...] o fator que mais se destaca nas pesquisas e reflexões acadêmicas sobre as relações entre Internet e religião apontam para a potencialização da autonomia individual religiosa, que se verifica na profusão de blogs, páginas pessoais, videologs; e também na iniciativa própria de evangelizar via-email, Twitter, Facebook e Orkut; [...].(BELLOTTI, 2012, p. 133)

Exemplo disso são as comunidades virtuais que se formam em torno da figura do padre Manzotti nas redes sociais, mas sem seu controle sobre as informações, como a "Comunidade Padre Reginaldo Manzotti""13 no Facebook. Trata-se de um fanpage sem declaração de autoria. Criada em janeiro de 2013, atualmente possui mais de 30 mil curtidas, nela são postadas imagens, orações e mensagens em nome do padre e da Associação Evangelizar é Preciso. Outra comunidade também no Facebook que utiliza a imagem do padre chama-se "Conselhos do Padre Reginaldo Manzotti - Notícias de personalidades" ${ }^{14}$. Criada em junho de 2013, com mais de 180 mil curtidas, a página alega reproduzir mensagens do padre Reginaldo, mas sem possuir vínculo com o mesmo. Nela, observa-se que grande parte das publicações divulgam eventos, feiras e produtos católicos nem sempre relacionados ao sacerdote. Bem como são compartilhadas várias publicações de um outro perfil do Facebook intitulado "Cidade da

\footnotetext{
${ }^{13}$ Fanpage "Comunidade Padre Reginaldo Manzotti" no Facebook. Acesso em: <https://www.facebook.com/pages/Padre-Reginaldo-Manzotti/437348903004206?sk=timeline>. Acesso em: 19 out. 2014.

${ }^{14}$ Comunidade "Conselhos do Padre Reginaldo Manzotti - Notícias de personalidades" no Facebook. Acesso em: 〈https://www.facebook.com/conselhosdopadrereginaldomanzotti?fref=ts>. Acesso em: 19 out. 2014.
} 
Fé” - que se trata de uma página com informações turísticas sobre a cidade de peregrinação de Aparecida/SP. Essas várias postagens de assuntos e origens diversos dão a impressão de que a imagem do padre Reginaldo é vinculada nesse perfil, com intuito de atrair a atenção de internautas e, ao mesmo tempo, legitimar ou dar credibilidade às postagens e ofertas que ali se encontram. Verifica-se, portanto, a forma através da qual no processo de midiatização religiosa o sacerdote comunicador, moldado pela mídia, perde nesse caminho o controle sobre sua imagem, mensagens e marcas (EINSTEN, 2012, p. 13).

\section{O comércio religioso online do Padre Reginaldo}

A partir da análise das fontes, averígua-se que em torno da marca "Padre Reginaldo Manzotti” desenvolve-se um extenso comércio religioso. Sua página na Internet oferece um link de acesso à "loja virtual Evangelizar é Preciso"15 (ver figura 11). Lá, o fiel tem acesso a uma infinidade de produtos que somam 234 itens diferentes, com valores variantes entre $\mathrm{R}$ \$ 2,50 (chaveiros) e R \$ 120,00 reais (Bíblia Edição Luxo). O comércio é organizado por categorias como: Artigos Religiosos (que incluem terços simples ou vendidos em recipientes perfumados, escapulários, capelas em madeira, joias como cordões e colares com medalhas de santos e até mesmo um kit composto por óleo, água benta e sal); também são ofertados CDs e DVDs do padre; produtos na categoria "Espaço Crianças" que carregam a marca "Manzottinho" (como livros, revistas, roupas infantis, bonecos e medalhões de berço); sessão de Livraria e Papelaria (com livros do padre Reginaldo e de outros sacerdotes ascendentes na mídia - publicados pela editora Evangelizar é Preciso, inclusive Bíblias em diferentes modelos e cores (como uma na cor rosa e com fecho estilizado), além de cadernos, selos postais com a imagem do padre e a marca dos Correios, entre outros). Na Loja destacam-se também as seções Presentes (com chaveiros, canetas, canecas e copos personalizados com imagens do padre, de santos ou da Associação Evangelizar) e Vestuário (que inclui chinelos, camisetas e camisas também carregando as mesmas marcas e imagens dos Presentes). O devoto também pode adquirir kits formados a partir da combinação de produtos de diferentes categorias. Alguns produtos são promovidos especialmente com base em datas comemorativas como o Natal. Os compradores também podem contar com a

\footnotetext{
${ }^{15}$ Loja Virtual Evangelizar é Preciso. Disponível em: 〈http://www.padrereginaldomanzotti.org.br/loja〉. Acesso em: 18 out. 2014.
} 
comodidade do serviço de entrega dos produtos adquiridos na Loja, e os comerciantes com um canal para registro de revendedores.

\section{« Voltar para o portal Padre Reginaldo Manzotti}

\section{Loja Virtual \\ Evangelizar é Preciso}

\begin{tabular}{|l|}
\hline Seleções Especiais \\
\hline Página Inicial \\
\hline Natal \\
\hline 10 Anos Experiência de \\
Deus \\
\hline Promoções! \\
\hline Lançamentos \\
\hline Categorias \\
\hline
\end{tabular}

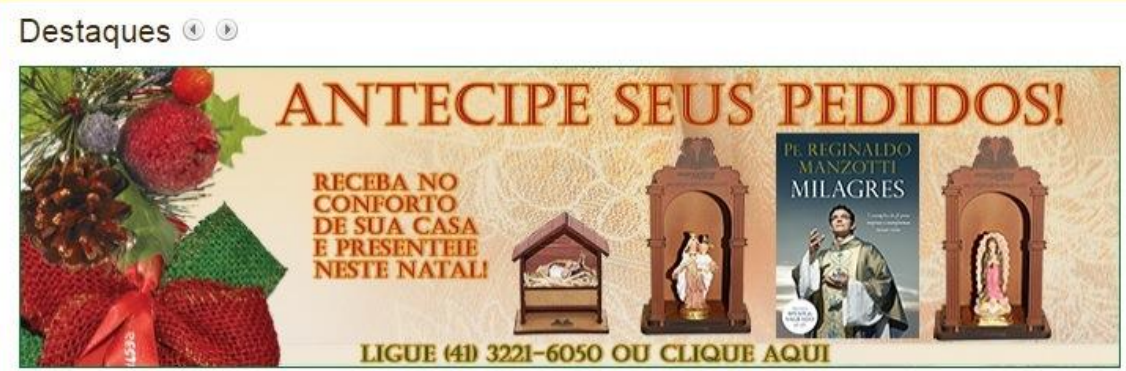

\begin{tabular}{|l|}
\hline Artigos Religiosos \\
\hline CDs e DVDs \\
\hline Espaço Crianças \\
\hline Kits \\
\hline
\end{tabular}

Kits

Livraria e Papelaria

Mini Livro

Presentes

Vestuário

(NOVO!)

Torne-se um revendedor »

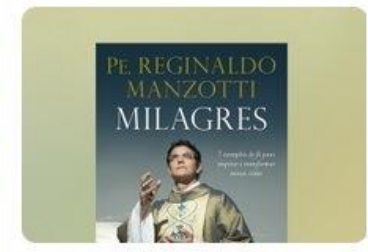

Livro Milagres - trilogia

$\mathrm{R} \$ 21,90$ Sinais do Sagrado

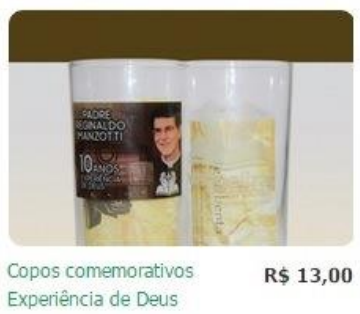

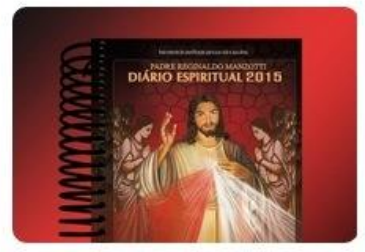

$\operatorname{R\$ } 22,10$

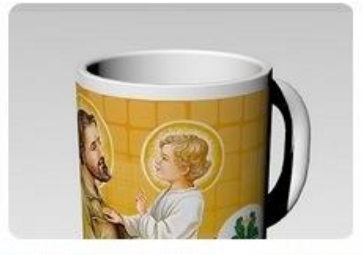

Caneca São José - rogai $\quad$ R\$ 23,00 pelas familias

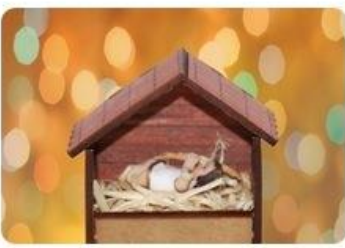

Manjedoura com Menino R\$23,00 lesus

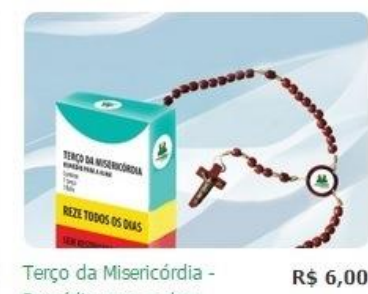

Figura 01 Loja Virtual Evangelizar é preciso - contendo 234 iténs

Fonte: <HTTP://WWW.PADREREGINALDOMANZOTTI.ORG.BR/LOJA>. ACESSO EM 18/10/14.

Observa-se que também em seus produtos o padre Reginaldo apropria-se da imagem de santos e a utiliza para estampar diversos itens disponíveis na loja virtual. Renata Menezes aborda esse fenômeno da popularidade dos santos no comércio religioso: "os santos estão, assim, fashion: eles se fazem presentes no circuito da moda, em roupas, acessórios, objetos de decoração. Uma onda de oratórios, relicários, escapulários, terços, camisetas [...]" Menezes (2009, p. 110-111).

Também no portal virtual do padre Manzotti, o devoto tem acesso a mais um produto, que se trata da oferta de vagas em dezenas de caravanas - com objetivo de levar fiéis de várias partes do Brasil aos eventos do padre. Elas são organizadas a partir 
de estados como o Paraná, Minas Gerais, São Paulo, Mato Grosso, entre outros. Essas caravanas também são divulgadas em redes sociais do sacerdote, programas de TV e rádio.

Essa intensa comercialização de produtos religiosos associados à fé remete às recomendações do Vaticano, que solicitam prudência nesse aspecto por seu caráter de incentivador do consumo:

Um dos campos de investigação (da Igreja) diz respeito à hipótese de que a vasta gama de opções relativas aos produtos e serviços de consumo, disponíveis na Internet, pode ter um efeito excessivo sobre a religião e encorajar uma abordagem « consumista » no que se refere à fé. Os dados indicam que alguns utentes que visitam os web sites religiosos podem vir a encontrar-se numa espécie de liquidação, seleccionando e escolhendo elementos religiosos uniformizados que correspondam aos seus gostos pessoais ${ }^{16}$.

Também se observam outras ações monetárias no portal do padre, mas vinculadas diretamente à Associação Evangelizar é Preciso. Como, por exemplo, o Jornal do Evangelizador, que é publicado mensalmente, mas distribuído somente aos associados que contribuem com doações mensais à entidade. O fiel também pode doar capelinhas, como a "Capela de Jesus Misericordioso", com valores que variam entre R\$ 100,00 e R\$ 2.000,0017. Da mesma forma, através do link "Gerar Boleto de Contribuição", o devoto é convidado a "colaborar da forma mais generosa possível" por meio de doações monetárias à Associação, através de boleto ou via Internet com cartão de crédito.

A questão do consumo religioso remete à ideia de materialismo, condenado publicamente pelo papa Bento XVI como uma "praga da sociedade moderna"18. O comércio religioso praticado pelo padre Reginaldo - enquanto representante do catolicismo, explicita a participação da religião, especialmente a virtualizada, no fenômeno de consumo contemporâneo. O consumo moderno de massa vinculado à cultura material, apontado por Daniel Miller, contrapõe o envolvimento das religiões com o materialismo; relação na qual, conforme o autor, religiões como o hinduísmo e o budismo expressam mais fortemente o antimaterialismo quando comparadas ao cristianismo (MILLER, 2007, p. 33-63). Para McDannell (2014), os cristãos precisam

\footnotetext{
${ }^{16}$ Igreja e Internet (28 de Fevereiro de 2002). op. cit. Item 9.

${ }^{17}$ Disponível em: <http://www.padrereginaldomanzotti.org.br/info_capelinha.html?ref=minibanner>. Acesso em: 18 out. 2014.

18 Papa condena materialismo. Disponível em: <http://g1.globo.com/jornalhoje/0,,MUL758961-16022,00PAPA+CONDENA+MATERIALISMO.html>. Acesso em: 15 out. 2014.
} 
construir a religião em seu espaço, comprando imagens de devoção para suas casas e mantendo "lembranças especiais de sua fé acerca de seus corpos". Para a autora, a interação contínua com imagens e objetos gera uma religiosidade particular. Contudo, nesse processo, por vezes, as fronteiras entre o sagrado e o profano não ficam claramente definidas como, por exemplo, quando objetos religiosos ao invés de caráter devocional passam a um elemento ornamental (MCDANNELL, 1995). Características claramente observadas em objetos vendidos pelo padre Manzotti, como o "medalhão de berço com estampas de santos". Talvez tenha sido com base na percepção dessa necessidade de "afirmação de fé" do cristão a partir do material, que o padre Reginaldo tenha atentado para a criação em seu portal, por exemplo, de uma loja virtual de produtos religiosos, bem como montado uma estrutura online para a organização de dezenas de caravanas para locais de peregrinação e adoração.

Ao tratar do materialismo especificamente católico, Orsi (2014) atenta para a "fé materializada" do catolicismo que, segundo ele, trata-se de uma cultura religiosa a qual oferece muitas possibilidades materiais, exploradoras dos sentidos. Fato que pôde ser percebido tanto no ministério online do padre Reginaldo, como através da venda dos seus produtos. Por meio da evangelização digital, se observa que o padre faz uso intenso de recursos audiovisuais como música, vídeos e imagens, bem como substitui o contato físico dos fiéis com suas imagens sagradas reais, pela "adoração virtualizada". Mas é através da oferta dos seus produtos, por meio da exploração estética e a mescla de sensações (como, por exemplo, o "terço perfumado na rosa", a bíblia estilizada, ou mesmo a venda de água benta), que o sacerdote funde o símbolo e o significado do sagrado com o consumo profano, e este último passa então a integrar um "comércio santificado" - legítimo pela imagem de um sacerdote e pela sacralização do ambiente virtual.

\section{Vinculação da marca Padre Reginaldo com a Associação Evangelizar É Preciso}

A Associação Evangelizar é Preciso idealizada pelo padre em 2005, conta com o apoio da arquidiocese de Curitiba e objetiva a evangelização através dos meios de comunicação. De acordo com informações do site do padre Reginaldo, através do setor "Expansão" da instituição (rádio e TV Evangelizar é Preciso), criado em 2007, são firmadas parcerias e garantidas as retransmissões ao vivo dos programas radiofônicos e 
televisivos do padre Reginaldo Manzotti. O setor "Comercial Evangelizar é Preciso", é responsável por comercializar os inúmeros "produtos destinados à evangelização" com a marca da instituição. De acordo com o release da organização, os produtos Evangelizar é Preciso "são desenvolvidos a partir de pesquisas de mercado"19.

Analisa-se que, quando se trata da vinculação da imagem e da marca Padre Reginaldo Manzotti à imagem da Associação enquanto entidade social, no sentido de uma obra de evangelização sem fins lucrativos ou interesses políticos, a parceria é bem definida e divulgada. Em suas redes sociais e em seu portal na Internet, o padre Reginaldo deixa claro que não cobra cachê, apenas aceita caridade por suas participações em eventos católicos; sendo que todas as rendas obtidas são revertidas à associação. No perfil da Associação no Facebook também são descritos seus trabalhos sociais de auxílio a comunidades carentes:

Com sede em Curitiba, a Obra presta assistência social às comunidades e instituições carentes de Curitiba e Região Metropolitana oferecendo atendimento gratuito nas áreas de direito, psicologia e nutrição, realizando palestras educativas e ações sociais em hospitais, asilos, creches, orfanatos e regiões sem infraestrutura, onde seus voluntários também prestam apoio espiritual e atendem necessidades locais, doando roupas, mantimentos e produtos de limpeza e higiene pessoal ${ }^{20}$.

Verifica-se por fim, que essa vinculação da marca Evangelizar é Preciso - uma obra de caráter também beneficente -, com produtos e programas da própria associação e também do Padre Reginaldo Manzotti, pode estar relacionada a uma ação mercadológica: o marketing de causa-relacionada. Também conhecido como "responsabilidade social corporativa ou ainda filantropia corporativa", Mara Einstein define como uma "tentativa de amarrar uma instituição de caridade a um produto para gerar vendas para o produtor e fundos para a caridade". Em um comparativo com os Estados Unidos, por exemplo, a autora aponta que em mercados emergentes como o Brasil, os consumidores tem maior propensão que os americanos em comprar e divulgar marcas que apoiam causas tidas como nobres (EINSTEN, 2012, p. 30).

\footnotetext{
${ }^{19}$ Página oficial do Padre Reginaldo Manzotti na Internet, op. cit.

${ }^{20}$ Perfil da Associação Evangelizar é Preciso no Facebook. Disponível em:

<https://www.facebook.com/evangelizarepreciso/info>. Acesso em: 20 ago. 2014.
} 


\section{A transformação da religiosidade no espaço virtual}

No Brasil a religião está presente na Web de forma cada vez mais intensa e expansiva (PUNTEL, 2008, p.141), não só o catolicismo como diversas outras religiões concorrentes. Nesse cenário, as mensagens religiosas são transmitidas no intento de atingir, além dos adeptos já cativos, o público de fiéis potenciais (SOUZA, 2005, p.158). De forma geral, observa-se que o padre Reginaldo segue esse direcionamento, inovando em muitas práticas virtualizadas e, ao mesmo tempo, buscando manter no ciberespaço ritos e práticas religiosas tradicionais do catolicismo (MOREIRA, 2012, p. 124).

Analisa-se que no espaço digital a utilização de novos recursos permitiu uma reconfiguração das práticas religiosas habituais do catolicismo, ou seja, alteram-se as formas tradicionais dos rituais religiosos para novas práticas da fé. Conforme Teixeira (2009, p. 18) trata-se de uma "destradicionalização" do campo religioso:

A 'releitura' ou re-representação das religiões nos ambientes e mundos virtuais, por exemplo de conteúdos, formas, ritos e doutrinas [...] ainda que pretendam ser apenas um 'complemento' ou uma 'continuação' da prática usual nas igrejas e templos físicos, [...] vai levar a um refazimento e desenvolvimento ulterior das religiões. (MOREIRA, 2012, p. 123)

Observa-se que atualmente, as religiões tradicionais coexistem com uma realidade de diversidade religiosa e de crenças, sendo que nesse espaço, de forma geral, os indivíduos já não se atêm de forma tão intensa a doutrinas e tradições (HOOVER, 2012, p. 54). A globalização altera o quadro religioso das diferentes camadas da sociedade, o qual adquire uma tendência de pluralização e de ameaça às religiões tradicionalmente dominantes (MARIZ, 2006, p. 53). É nesse contexto que o catolicismo oficial depara-se com um processo de declínio, frente a uma sociedade caminhando para a secularização, processo em que as religiões "são menos normativas para o conjunto da sociedade" Rumstain e Almeida (2009, p. 52) Além do que, como menciona Teixeira (2009), o público confia cada vez menos na religião e em suas autoridades institucionalizadas. Da fragilização dessa estrutura religiosa tradicional, decorre uma metamorfose do religioso em uma diversidade de outras formas de expressão:

No campo aberto do 'pluralismo da oferta religiosa' encontra-se um sujeito que se liberta do modelo único de exercício da tradição, vive uma experiência de autonomia que lhe possibilita escolher livremente a forma de sua adesão, seja na forma religiosa de convertido, de peregrino ou mesmo sem religião. (TEIXEIRA, 2009, p. 162) 
Além da destradicionalização, trata-se de um fenômeno de desinstitucionalização religiosa. Os indivíduos possuem liberdade e autonomia em suas ações espirituais e religiosas (BELLOTTI, 2012, p. 133), especialmente no mundo digital. E é nesse contexto, que o padre Reginaldo expande as práticas do catolicismo tradicional, incluindo "movimentos, imagens e práticas menos formais e mais populares" Hoover (2012, p. 54), adequando-as a um novo espaço da religiosidade, o mundo virtual.

\section{Considerações Finais}

Este artigo buscou expor as complexas e dinâmicas relações entre mídia e religião católica, bem como analisar as diferentes formas de religiosidade daí derivadas, também enquanto manifestações histórico-culturais. A diversidade de práticas religiosas decorrentes do acelerado avanço tecnológico e das mídias digitais nas últimas duas décadas, somado à crescente democratização de acessos a esses recursos (AOKI; MACHADO, 2010, p. 106-122) - em um país com cerca de 125 milhões de adeptos (TEIXEIRA, 2009, p. 162) -, fornece uma dimensão da amplitude desse campo de estudo. Também a expansão comunicacional religiosa, enquanto reflexo de uma relação histórico-evolutiva, entre catolicismo e mídia de massa, ilustra a adaptação da religião às novas sociedades.

Inserido neste contexto, o conjunto de ações comunicacionais do padre Reginaldo na Internet, representa claramente a autonomia tanto do sacerdote como dos fiéis em relação à religiosidade; da mesma forma que expõe a modernização que o ambiente virtual impõe sobre as práticas religiosas tidas como tradicionais (AOKI; MACHADO, 2010, p. 106-122). Uma reconfiguração da prática religiosa resultante: da autonomia dos fiéis (BELLOTTI, 2012, p.130), da apropriação de práticas populares pelo próprio sacerdote, e da inserção de diversos aspectos estéticos e hipermidiáticos a essas práticas. Igualmente, as práticas do padre Reginaldo Manzotti revelam uma releitura, exigida pelo ciberespaço, da ambiência do sagrado, que passa do espaço físico à consagração do virtual. Dessa forma, o sacerdote arrasta para a Web sua pregação, práticas e crenças do mundo "real", estreitando o relacionamento com seus fiéis através de novos canais, que apresentam fácil acessibilidade, permitem maior interação e participação do indivíduo na religião, e abrem espaço para uma religiosidade 
personalizada - mediada e associada à figura do comunicador. Em outro aspecto, observa-se que seu comércio religioso online atenua a fronteira entre o sagrado e o profano e, como exemplificam os produtos e ações ligadas ao padre na Internet, os dois conceitos tidos como opostos perdem sua delimitação e passam a entrelaçar-se no ciberespaço.

Por fim, esse estudo abre caminho para outras questões de pesquisa relacionadas à evangelização midiática e ao padre Reginaldo, como o impacto das práticas do sacerdote especificamente sobre o público católico de Curitiba e região, inclusive no que se refere à discussão da religiosidade virtual como substitutiva da presencial. Como também uma investigação com os adeptos do padre comunicador a respeito do fenômeno da autonomia religiosa dos fiéis, que passam a adotar uma postura menos passiva em relação à religião. 


\section{Referências}

AOKI, Cintia. MACHADO, Fátima Regina. Acesso ao Divino: a utilização de recursos digitais para práticas religiosas católicas. REVER: Revista de Estudos da Religião. Sep. 2010, Vol. 10, p. 106-122. Disponível em: <http://revistas.pucsp.br/rever/rv3_2010/i_aoki.html>. Acesso em: 02 jun. 2014.

BELLOTTI, Karina K. As Religiões Tradicionais e a Internet. In: MOREIRA, Aberto da S.; LEMOS, Carolina T.; QUADROS, Eduardo de G. (organizadores). A Religião na Mídia e a Mídia na Religião. Goiânia: América, 2012. p. 127-135.

EINSTEIN, Mara. Religião, Mídia e Marketing. In: MOREIRA, Alberto da S.; LEMOS, Carolina T.; QUADROS, Eduardo de G. (organizadores). A Religião na Mídia e a Mídia na Religião. Goiânia: América, 2012. p. 17-18.

HOOVER, Stewart M. A Mídia e suas Linguagens Religiosas (tradução: Alberto da S. Moreira e Aurélia S. Borsato). In: MOREIRA, Aberto da S.; LEMOS, Carolina T.; QUADROS, Eduardo de G. (organizadores). A Religião na Mídia e a Mídia na Religião. Goiânia: América, 2012. p. 47-56.

MARIZ, Cecília Loreto. Catolicismo no Brasil contemporâneo: reavivamento e diversidade. In: TEIXEIRA, Faustino; MENEZES, Renata (orgs.). As Religiões no Brasil: continuidades e rupturas. Rio de Janeiro: Vozes, 2006. Capítulo 4, p. 53-68.

MCDANNELL, Colleen. Material Christianity. In: Material History of American Religion Project (tradução livre). Disponível em: <http://www.materialreligion.org/journal/material.html>. Acesso em: 25 out. 2014.

MENEZES, Renata. Santo Antônio no Rio de Janeiro: dimensões da santidade e da devoção. In: TEIXEIRA, Faustino; MENEZES, Renata (orgs.). Catolicismo plural: dinâmicas contemporâneas. Petrópolis: Vozes, 2009. Capítulo 6. p. 109-134.

MILLER, Daniel. Consumo Como Cultura Material. Horizontes Antropológicos, Porto Alegre, ano 13, n. 28, p. 33-63, jul./dez. 2007. Disponível em: $\langle$ http://www.scielo.br/scielo.php?pid=S0104-71832007000200003\&script=sci_arttext $>$. Acesso em: 10 out. 2014.

MOREIRA, Aberto da S. O Sagrado nos Mundos Virtuais. In: MOREIRA, Aberto da S.; LEMOS, Carolina T.; QUADROS, Eduardo de G. (organizadores). A Religião na Mídia e a Mídia na Religião. Goiânia: América, 2012. p. 112-124.

ORSI, Robert. The material world of Catholic childhood. In: Material History of American Religion Project (tradução livre). Disponível em: <http://www.materialreligion.org/journal/children.html>. Acesso em: 25 out. 2014.

PAPA PAULO VI. Decreto Conciliar Inter Mirifica: sobre os meios de comunicação social (4 de Dezembro de 1963). In: Documentos do Concílio Vaticano II. Disponível em:

$<$ http://www.vatican.va/roman_curia/pontifical_councils/pccs/documents/rc_pc_pccs_doc_0412 1963_inter-mirifica_po.html>. Acesso em: 16 maio 2014.

PUNTEL, Joana T. Catolicismo e Mídia no Brasil. In: MOREIRA, Aberto da S.; LEMOS, Carolina T.; QUADROS, Eduardo de G. (organizadores). A Religião na Mídia e a Mídia na Religião. Goiânia: América, 2012. p. 33-46.

Cultura Midiática e Igreja: uma nova ambiência. São Paulo: Paulinas, 2008.

PUNTEL, Joana T., CORAZZA, Helena. Pastoral da Comunicação: diálogo entre fé e cultura. São Paulo: Paulinas, 2007.

RUMSTAIN, Ariana. ALMEIDA, Ronaldo de. Os Católicos no Trânsito Religioso. In: TEIXEIRA, Faustino; MENEZES, Renata (orgs.). Catolicismo plural: dinâmicas contemporâneas. Petrópolis: Vozes, 2009. Capítulo 3. p. 31-56. 
SBARDELOTTO, Moisés. "E o Verbo se fez bit": uma análise de sites católicos brasileiros como ambiente para a experiência religiosa. 2011. 207 p. Dissertação (Mestrado em Comunicação) - Faculdade de Ciências da Comunicação. Universidade do Vale do Rio dos Sinos, São Leopoldo. p. 35-181. Disponível em: $<$ http://biblioteca.asav.org.br/vinculos/tede/MoisesSbardelottoComunicacao.pdf >. Acesso em: 08 nov. 2014.

SOUZA, André Ricardo de. Igreja in concert: padres cantores, mídia e marketing. São Paulo: Annablume: Fapesp, 2005.

TEIXEIRA, Faustino. A conjuntura internacional católica: a relação com as religiões. In: TEIXEIRA, Faustino; MENEZES, Renata (orgs.). Catolicismo plural: dinâmicas contemporâneas. Petrópolis: Vozes, 2009. Capítulo 9. p. 159-180.

Faces do Catolicismo Brasileiro Contemporâneo. In: TEIXEIRA, Faustino; MENEZES, Renata (orgs.). Catolicismo plural: dinâmicas contemporâneas. Petrópolis: Vozes, 2009. Capítulo 2. p. 17-30.

Comunidade "Conselhos do Padre Reginaldo Manzotti - Notícias de personalidades" no Facebook. Acesso em: <https://www.facebook.com/conselhosdopadrereginaldomanzotti?fref=ts>. Acesso em: 19 out. 2104.

Entrevista com Moisés Sbardelotto autor do livro E o Verbo se fez Bit - A comunicação e a experiência religiosas na internet. Disponível em:

$<$ http://editorasantuario.wordpress.com/2012/11/09/entrevista-com-moises-sbardelotto-autordo-livro-e-o-verbo-se-fez-bit-a-comunicacao-e-a-experiencia-religiosas-na-internet/>. Acesso em: 20 out. 2014.

Fanpage "Comunidade Padre Reginaldo Manzotti" no Facebook. Acesso em: <https://www.facebook.com/pages/Padre-Reginaldo-

Manzotti/437348903004206?sk=timeline>.Acesso em: 19 out. 2014.

Igreja e Internet (28 de Fevereiro de 2002). In: Conselho Pontifício para as Comunicações Sociais.

$<$ http://www.vatican.va/roman_curia/pontifical_councils/pccs/documents/rc_pc_pccs_doc_2002 0228_church-internet_po.html>. Acesso em: 07 jul. 2014.

Instrução Pastoral Communio et progressio (23 de Maio de 1971). In: Conselho Pontifício para as Comunicações Sociais. Disponível em:

<http://www.vatican.va/roman_curia/pontifical_councils/pccs/documents/rc_pc_pccs_doc_2305 1971_communio_po.html_. Capítulo 2, item 128. Acesso em: 07 jul. 2014.

Loja Virtual Evangelizar é Preciso. Disponível em: <http://www.padrereginaldomanzotti.org.br/loja〉. Acesso em: 18 out. 2014.

Página oficial do Padre Reginaldo Manzotti na Internet. Disponível em <http://www.padrereginaldomanzotti.org.br/>. Acesso em: 06 jun. 2014.

Papa condena materialismo. Disponível em: <http://g1.globo.com/jornalhoje/0,,MUL75896116022,00-PAPA+CONDENA+MATERIALISMO.html>. Acesso em: 15 out. 2014.

Perfil da Associação Evangelizar é Preciso no Facebook. Disponível em: <https://www.facebook.com/evangelizarepreciso/info>. Acesso em: 20 ago. 2014.

Programa Mais Você com Ana Maria Braga exibido em 25/12/2012. Disponível em: <https://www.youtube.com/watch?v=vQEZBrcy3NQ>. Acesso em: 25 set. 2014.

Disponível em: <http://www.padrereginaldomanzotti.org.br/info_capelinha.html?ref=minibanner>. Acesso em: 18 out. 2014. 
Recebido: 11/10/2017

Received: 10/11/2017

Aprovado: 23/11/2017

Approved: 11/23/2017 